\title{
Please Do Not Pirate It, You Will Rob the Poor! An Experimental Investigation on the Effect of Donation on Piracy ${ }^{1}$
}

\author{
Gilles Grolleau \\ UMR INRA-ENESAD (CESAER) \\ 26 Bd Dr Petitjean BP 87999, 21079 Dijon Cedex France \\ Tel: + 33380772443 - Fax: + 33380772571 \\ grolleau@enesad.inra.fr \\ Naoufel Mzoughi \\ Université de Bourgogne - UMR INRA-ENESAD (CESAER) \\ 26 Bd Dr Petitjean BP 87999, 21079 Dijon Cedex France \\ Tel: + 33380772439 - Fax: + 33380772571 \\ mzoughi@enesad.inra.fr \\ Angela Sutan \\ Burgundy School of Business \\ CEREN - Département Management et Organisation des Hommes \\ Tél : + 33380725958 - Fax: + 33380725999 \\ asutan@escdijon.com
}

\begin{abstract}
Producers market products for which a part of the proceeds go to a charitable cause. Donations to such charitable causes may increase the moral intensity of piracy and consequently reduce the pirates' willingness to pirate. This rationale is empirically tested through a dual empirical strategy, that is, a market survey and a laboratory experiment. We show that piracy decreases when a donation mechanism is implemented. Nevertheless, for intermediate levels of transfer, piracy increases again. Results are interpreted and managerial implications stressed.
\end{abstract}

Key words: donations; moral barriers; piracy; social causes.

JEL codes: M31.

${ }^{1}$ The authors would like to thank Douadia Bougherara, Uri Ben-Zion, Håkan J. Holm, Nathalie Lavoie and Stanley Liebowitz for their useful comments. They also thank students from the Business school of Burgundy for research assistance. The usual disclaimer applies. 


\section{Please Do Not Pirate It, You Will Rob the Poor! An Experimental Investigation on the Effect of Donation on Piracy}

"Do not rob the poor because he is poor."

Proverbs 22:22

\section{Introduction}

The use of donations to social or charitable causes is well-known and widely practiced in the marketplace. For example, "a substantial portion of the proceeds received by Sony Music from sales of this album [God Bless America] will be donated to The Twin Towers Fund. The fund aids the families of Police, Fire, EMS and other City employees involved in rescue efforts surrounding the events of September 11, 2001"2. Several authors argue that such donations can constitute a means of increasing profits (Webb, 1996; Okten and Weisbrod, 2000). Several economic rationales have been explored to justify how donations can increase profits, such as capturing sensitive consumers and improving public image. Our analysis adds a new argument to the previous literature.

Concretely, donations to charitable causes can make pirates reducing their piracy. This induced behavior can be 'instrumentalized' by pirated firms to reduce piracy and subsequent costs due to anti-piracy devices. A simple example will make clear the underpinning of this intuitive rationale. Say a firm that sells records, e.g. CDs, DVDs. Rather than paying the full price, some pirates benefiting from the "technology push" fraud to get the records. Pirates justify their behavior by several reasons such as the unfair price of records, the unacceptable repartition of profits among producers and artists and the specific character of cultural products that should be affordable to all.

\footnotetext{
${ }^{2} \mathrm{http} / / /$ www.sonymusic.com/godblessamerica/main.html (visited on January, 30 ${ }^{\text {th }}, 2005$ ). For the Top 10 songs devoted to charitable causes, see http://www.youthnoise.com/page.php?page_id=464, visited on January, $30^{\text {th }}, 2005$.
} 
Assume further that the recording firm promises to refund a significant part of its proceeds, e.g., $20 \%$, to a charitable cause. The recording firm voluntarily ties a social cause to its private interests. The introduction of this donation to charitable causes may prevent a subset of the pirating population from frauding. Some may argue that pirates do not have high moral values and they are not likely to reduce their piracy activity because of donations. We assume that the whole pirating population includes several subsets of pirates according to their sensitiveness to donations. Sometimes consumers are not stricken with moral guilt when the "victim" is a business perceived to be rich and rapacious, and therefore can afford it. In other words, piracy is likely to generate more or less guilty feelings according to the status of the victim. In other words, some pirates may be insensitive to charitable donations while other pirates consider 'robbing the poor' more reprehensible than 'stealing from the rich' like Robin Hood ${ }^{3}$. Consequently, the later subset is likely to reduce its piracy activity. Indeed, pirates may feel guilty if they perceive pirating as stealing "the social cause", "robbing the poor", and consequently will be less likely to pirate. Interestingly, anecdotal evidence may be found on several websites that encourage people to buy the product instead of pirating it because of donations, like the following statement from a fan of Cat Stevens: "There are lots of good download sites, I use them. If I know the proceeds of a song are going to charity I wouldn't download it"4. Another website gives the following advice: "Remember, all proceeds go to the Christmas Wish Fund, SO BUY IT, DON'T COPY IT! $!^{5}$ " Moreover, during the show of 'les Enfoirés' in Toulouse (France) devoted to collecting funds to provide meals to poor people, "the artists repeated several times: do not copy it, else the benefits for the 'restos du coeur' will be lost and the solidarity

\footnotetext{
${ }^{3}$ See Rother, Larry. "In the Land of Sun and Music Pirates Play Robin Hood." New York Times 20 May 2001: Section 4, Page 3.

${ }^{4}$ http://catstevens.com/bboards/?action=readtopic\&topic=08731\&forum=001, visited on February, $6^{\text {th }}, 2005$.

${ }^{5} \mathrm{http} / / /$ polyphonia.co.uk/Eye+For+An+Eye-shop-group-music.asp, visited on January, $30^{\text {th }}, 2005$
} 
chain broken" (Le Monde, 18/06/04 ${ }^{6}$ ). Some individuals go further by giving numerical data on the benefits of not pirating: "Please do not pirate it (...) 100 CDs that are sold equal 1800 meals"7.

The remainder of this article is organized as follows. In section 2, we show why donations can reduce piracy. Section 3 presents the main results from a market survey. In section 4, we describe the experimental design and discuss the main results. Section 5 provides some managerial implications and concludes.

\section{Why donations to social causes may reduce piracy?}

Arguments frequently used to explain why people contribute voluntarily to public goods, e.g., altruism, warm glow (Andreoni, 1990), may be to some extent applied to the decrease in piracy due to charitable donations. In the following, we expose several reasons not mutually exclusive that can explain why pirates would reduce their piracy because of charitable donations.

First, according to Logsdon et al. (1994, quoted by Cheng et al., 1997), some kinds of piracy such as software piracy are perceived as an issue of 'low moral intensity'. Charitable donations associated to originals are likely to raise the perceived moral intensity about piracy at the individual level. Raising the perceived moral intensity increases the guilty feeling of pirates and reduces subsequently their willingness to pirate.

Second, frequently, pirates do not hold themselves accountable for their action but blame the producers that charge exorbitant prices for cultural goods (Ang et al., 2001).

\footnotetext{
${ }^{6}$ Le Monde, 18/06/04, Ne tirez pas sur les pianistes.

${ }^{7}$ http://www.infos-du-net.com/forum/page-10073_1_0.html visited on July, 9th, 2006.
} 
Session $11-45$

Consequently, piracy and faking are considered as a fair antidote to corporate profitmaking. In some plausible circumstances, charitable donations reduce the image that prices serve private profit purposes and legitimize their price as means to finance a social cause.

Third, some people value the image other people have of themselves. A recent literature has focused on status seeking behavior -there is a pressure to differentiate consumption, to prove and communicate a specific identity (Hirsch, 1976; Hemenway and Solnick, 2005). If robbing the poor (or pirating the social good) is visible and does not make a good impression on others and looking good is important for the pirates, such effect is likely to decrease the piracy rate (Ang et al., 2001). In certain plausible circumstances, other people may easily assess if the good (or its support, e.g., a CD or a DVD) is an original version or a pirated one. Moreover, while some people may justify (and eventually support) a Robin Hood's behavior (robbing the rich to help the poor), robbing a social cause is frequently perceived as a very unethical and unfair practice (Proverbs 17:17; Proverbs 22:22).

Fourth, there is also some indirect and anecdotal evidence that some pirates also exhibit a positive willingness to pay (but lower than the full price) that may be reinforced by charitable donations. In the same line, the UK non-governmental organization, Oxfam has launched a charity download site (bignoisemusic.com), expecting that young people will legally download music and contribute simultaneously to charitable causes ${ }^{8}$.

As mentioned above, the preceding arguments may not apply to all pirates but to a significant part of them. Indeed, some pirates may have moral values that will not be influenced by the mechanisms described above or may exhibit counter arguments (such

\footnotetext{
${ }^{8}$ Oxfam to launch UK's first charity download site. Music Week, 5/29/2004, p. 3
} 
as contributing to the social cause by other means). Some pirates may be just sensitive to the presence or lack of donation, in a binary logic, regardless of the percentage of the proceeds devoted to donation while others may adjust their piracy reduction according to the relative amount of donation.

Therefore, we explore the two following hypotheses:

H1: Donation reduces piracy.

H2: The higher the donation level is, the lower the piracy rate is.

\section{The market survey}

In April 2006, we conducted a market survey with a representative sample of 168 persons in the metropolitan area of Dijon, France ${ }^{9}$. It consisted in 40 questions in which several points related to the piracy activity and individual characteristics are surveyed. In the following, we report the results related to four issues: the anti-piracy punishment scheme (Are you afraid of the current legal anti-piracy punishment?), the involvement in charitable causes and its reasons (Do you contribute to charitable causes? Why?), the willingness to buy a "charitable" CD (Would you buy a CD on which a percentage of the profits are donated to a charitable cause?), and the percentage of proceeds devoted to charitable donation leading to buy the record (For which percentage of proceeds devoted to a charitable cause would you stop pirating and start buying the CD?). The main results are presented in table 1.

\section{[Insert table 1]}

\footnotetext{
${ }^{9}$ This market survey was conducted by some students of the Burgundy School of Business.
} 
The declarative intentions of potential "pirates" expressed in the market survey showed that the impact of a donation mechanism on the pirating behavior is a function of its reliability. In particular, we are interested in two determinants of the reliability of such a mechanism, i.e., the transparency degree of the action and the percentage donated to the charitable cause. These dimensions will be taken into account in the experiment. First, the rules and the effectiveness of the donation mechanism will be public. Second, the results of the market survey showed that such a mechanism is likely to be perceived as plausible in the short run for relatively small percentages of donation $(10 \%-15 \%)$. In the long run, the percentage of proceeds devoted to the charitable cause should increase to more than $75 \%$. The first result is related to a surprise effect, whereas the second is related to an involvement effect. Indeed, participants in the market survey declared to perceive the record producer as mainly profit-oriented. Therefore, contributing for a small percentage to a charitable cause remains credible as long as this action is consistent with the profit-maker role of the firm. Overtime, consumers are likely to raise doubts about the real motivations of the donation strategy, threatening its sustainability.

\section{The experiment: design and results}

\section{Market characteristics and schedule of a session}

The experimental market is composed of two types of agents: the consumers and the records producer. The experiment is completely decontextualized: endowments, profits and donations are made in different colored tickets until the end of the experiment and no reference is made to CDs or donations. At the beginning of the experiment, all agents receive an endowment: half of the "consumers" are high-endowed and the other half (very) low-endowed with yellow tickets. The records producer is endowed with red tickets. The consumers' activity in this experiment is to change their yellow tickets into 
red tickets. Indeed, only red tickets are valuable for them and can be transformed into real money at the end of the experiment. For the records producer, only yellow tickets are valuable. An official exchange rate (yellow tickets into red tickets) is communicated and all rules are common knowledge to participants.

The schedule of a session was as follows: 21 participants were involved in a session. The experiment took place in two different rooms. The participants were split into two groups, 20 consumers located into room $A$ and one producer located into $\operatorname{room} B$. Consumers were randomly endowed with high $(h)$ or low amounts $(l)$ of yellow tickets and were communicated a common exchange rate $(1 / r)$ of the yellow tickets into red tickets $(1$ yellow ticket $=r$ red tickets $)$. The exchange had to be done with the producer in room $B$, owing $r(10 h+10 l)$ red tickets in a box.

At the beginning of the session, the participants had to read the instructions, and then fill a short questionnaire to check their understanding of the game. In addition, the instructions were also explained orally by the experimenter in order to make them a common knowledge. The experimenter notably explained (1) that each participant has to go in room $B$ on a randomly basis in order to exchange the yellow tickets into red ones, and (2) that the agent in room $B$ could be absent from the room and thus participants might have to do the exchange themselves. Prior to the exchange, the participants were asked to indicate on a sheet of paper the number of yellow tickets that they would deposit and the number of red tickets they would take if they were the first to go into the room $B$. The sheet of paper was handled to the experimenter. Finally, the participants started to go sequentially and exchange their tickets in room $B$. In sessions with a donation mechanism, participants had to go back to the room $A$ and wait for the 
donation distribution. In sessions without donation, participants had to go directly to receive the monetary value of their red tickets.

As this experimental setting attempts to mimic the piracy activity, several constraints were imposed to participants:

$\checkmark$ Because a pirate could be caught, the participants were informed of the possibility that the agent in room $B$ had to control if the exchange has been fairly done, i.e., at the official exchange rate. The probability to be controlled was common knowledge and was low (2 times out of 20) similar to real life where these controls are scarce.

$\checkmark$ Pirating and downloading are time consuming. So, we introduced in the exchange mechanism the obligation to staple red tickets on a sheet of paper before transforming the red tickets into real money. Moreover, too much piracy may threaten the downloading and leads to its closing. Thus, the maximum number of red tickets that an agent could take was not communicated to agents, but the sheet of paper on which the red tickets had to be stapled had only 20 boxes. It was made clear for participants that only stapled red tickets could be exchanged into money and that only one ticket could be stapled per box.

The donation mechanism was implemented as a percentage (denoted $d$ ) of the yellow tickets in room $B$ after all participants in room $A$ finished the exchange. These tickets were redistributed among low endowed agents at the end of the experiment. Only in this case yellow tickets were valuated and exchanged into money. Obviously, if the official exchange rate $r$ is not respected by all exchangers, some consumers in room $A$ 
Session $11-50$

would not find red tickets and thus would not have the opportunity to exchange. Let $p$ be the percentage of participants who actually have the opportunity to exchange ( $20 \mathrm{p}$ is therefore their real number in each session). Let further $r_{i}^{r h}$ (respectively $r_{i}^{r l}$ ) be the exchange rate used by participant $i$ in the high (respectively low) endowment group. Finally, let $s$ be the show up fee, i.e., the gain related to the participation to the experiment.

The average outcome of participant $i$ in the high endowment group is:

$$
p\left(s+h r_{i}^{r h}\right)+(1-p) s
$$

The average outcome of participant $i$ in the low endowment group is:

$$
p\left[s+l r_{i}^{r l}+\frac{1}{10}(10 h+10 l) p r d\right]+(1-p)\left[s+\frac{1}{10}(10 h+10 l) p r d\right]
$$

with $(10 h+10 l) p r$ the outcome of the producer. No effective controls are taken into account in these formulas. The dominant strategy for consumers is to increase the real exchange rate $r^{r}$.

Three sessions were conducted with 63 participants in April 2006 in the Business School of Burgundy in Dijon. Participants were student in various fields and of various degrees. They received a show up fee of $€ 5$ (i.e., $s=5$ ) and the money earned during the experiment. The experiment lasted 45 minutes and participants earned between $€ 5$ and $€ 25$. The parameters of each session are reported in table 2 . 


\section{[Insert table 2]}

\section{Results and discussion}

As mentioned above, three experimental sessions were conducted. According to the market survey results, we should implement a low, a moderate and a very high donation scheme. As the very high donation scheme is unlike to hold in real life, we only test in this experiment a low (10\%, session 2) and a moderate (30\%, session 3$)$ donation scheme. Our benchmark treatment (session 1) is a non-donation experiment. The main results are presented in table 3.

\section{[Insert table 3]}

R1: The Percentage of piracy is significantly lower when a donation mechanism is present (Table 3, last column). Consequently, the number of real exchanges is significantly higher in sessions in which a donation mechanism is implemented.

$R 2$ : When no donation mechanism is implemented (session 1), the number of effective exchanges is the lowest, the rate of piracy (measured by the non-respect of the official exchange rate) is the highest, the declarative and real exchange rate are the lowest, and, the rate of ethical dissonance is the lowest. In sum, donation does not reduce piracy for intermediate levels of transfer. The relation between donation (as a percentage of proceeds) and the piracy rate is likely to follow a roughly $U$ shaped curve.

This result can be intuitively interpreted in terms of piracy elasticity. A piracy elasticity $\varepsilon$ for a given product measures the responsiveness of piracy for this product to a given change in the amount of donation $d$, i.e., the proceeds percentage devoted to a social cause. Using the conventional equation in the case of a continuous and derivable 
function, the piracy elasticity $\varepsilon$ is given by $\varepsilon=\frac{\frac{d x}{x}}{\frac{d D}{D}}$ where $d x$ corresponds to the variation in the piracy rate. $d D$ corresponds to a small change in the percentage of proceeds devoted to the social cause. Note that $\Delta D>0$ because we postulate an increase of the donation, a higher percentage of the price is devoted to social causes. From an efficiency viewpoint, producers have incentives to choose social causes that reduce the most the piracy rate for a given amount of donation.

\section{Managerial implications and conclusive remarks}

We showed that donations to charitable causes matter for some pirates. Nevertheless, the relationship between donations and piracy is not linear and requires further investigation. In spite of some limitations, some managerial implications can be drawn from our study. Indeed, donations to charitable causes are likely to serve several non mutually exclusive purposes such as improving company's public image and increasing sales. We suggested an additional factor, that is, donations can make pirates reducing their fraudulent activity because of an increase in the moral intensity of the piracy. In other words, the pirates steal not a rich but a poor what is generally recognized as more condemnable. Consequently, donations to charitable causes can be 'instrumentalized' by pirated firms or may simply constitute a byproduct of other motivations, e.g., improving the company's image or altruistic behavior. In this case, the piracy reduction can be considered as an unintended effect. In some plausible circumstances, donations can constitute a profitable substitute to anti-piracy devices.

Moreover, the rationale developed above opens a door to original anti-piracy strategies. Indeed, without neglecting capitalistic (e.g., technological devices preventing fraudulent copies) and regulatory alternatives (e.g., monitoring investments to threat of 
Session $11-53$

severe sanctions against pirates), taking into psychological and moral factors may lead managers to increase 'moral barriers' for pirates. The strategic use of charitable causes to increase the moral intensity of the piracy activity requires a good knowledge of pirates and of their perceptions on different causes. Although we have not investigated this dimension, the effectiveness of the mechanism described in this paper depends, at least partly, on the ability of the producer to convince pirates that the only and best way to help the charitable cause is to buy the product. Indeed, if this exclusivity is not guaranteed, pirates are likely to continue pirating, stating they are helping the charitable cause by another way. The mechanism studied here constitutes an illustrative example, but we contend that several other similar strategies may be implemented in the real marketplace. An additional and insightful point that deserves attention relates to the 'beneficiary' of the strategy. In more mundane words, pirates may consider that the donation affects only the product on which the promise is made or indicates an ethical behavior of the producer. In the former case, the overall effect may remain somewhat limited while in the later, the ethical perception may spillover all products of this producer, making the strategy significantly more profitable. Last but not least, although we have focused our attention on the recording industry, the framework and the results are generic and can be extended to other products.

In other words, all social causes are not equal. The percentage of proceeds devoted to the social cause and the characteristics of the social cause are likely to influence the extent to which pirates modify their behavior. Some social causes can be emblematic and donations devoted to these causes raise significantly more the moral intensity of piracy than other causes. For example, the piracy rate is likely to be lower (maybe, the lowest) for products devoting their whole proceeds to the social cause such as the 
'What's Going On?' devoted to AIDS relief efforts and the United Way's September 11 Fund $^{10}$.

\section{References}

Andreoni J., 1990. Impure Altruism and Donations to Public Goods: A Theory of Warm-Glow Giving? Economic Journal, 100: 464-477.

Ang, SH.; Cheng, PS.; Lin, EAC.; Tambyah, SK., 2001, Spot the Difference: Consumer Responses Towards Counterfeits, Journal of Consumer Marketing, 18(3): 219-235.

Cheng, HK; Sims, RR.; Teegen, H., 1997, To Purchase or Pirate Software: An Empirical Study, Journal of Management Information Systems, 13(4): 49-60.

Hemenway, D., Solnick, S., 2005. Are positional Concerns Stronger in Some domains than in Others? American Economic Review, 95(2):147-151.

Hirsch, F., 1976, Social Limits to Growth, Harvard University Press, Cambridge.

Okten, C. Weisbrod, B. A., 2000, Determinants of Donations in Private Nonprofit Markets, Journal of Public Economics, 75, pp. 255-272.

Webb, N. J., 1996, Corporate Profits and Social Responsibility: "Subsidization" of Corporate Income Under Charitable Giving Tax Laws, Journal of Economics and Business, 48, pp. 401-421.

\footnotetext{
${ }^{10}$ The sensitiveness of people to a charitable is frequently higher at some given times, e.g., just after a catastrophic event. Consequently, this temporal dimension can be used to increase the effectiveness of the donation strategy, from the firm viewpoint.
} 


\section{Session 11 - 55}

Table 1: Main results from the market survey

\begin{tabular}{ll}
\hline \multicolumn{1}{c}{ Question } & \multicolumn{1}{c}{ Answers } \\
\hline $\begin{array}{l}\text { Are you afraid of the current legal anti-piracy } \\
\text { punishment? }\end{array}$ & $60 \%$ do not fear the legal anti-piracy sanctions \\
\hline Do you contribute to charitable causes? Why? & $\begin{array}{l}60 \% \text { of the persons are involved in a charitable } \\
\text { cause. They donate mainly to well known } \\
\text { associations because of the "feeling to help". }\end{array}$ \\
\hline $\begin{array}{l}\text { Would you buy a CD on which a percentage of the } \\
\text { profits are donated to a charitable cause? }\end{array}$ & $\begin{array}{l}\text { Less than } 50 \% \text { really buy charitable CDs, because } \\
\text { they perceive the donation as a "new tax", "a } \\
\text { cosmetic device" on which the real distribution of } \\
\text { the profits is not clear. }\end{array}$ \\
\hline $\begin{array}{l}\text { For which percentage of proceeds devoted to a a } \\
\text { charitable cause would you stop pirating and start } \\
\text { buying the CD? }\end{array}$ & $\begin{array}{l}30 \% \text { of the people think that the percentage of } \\
\text { donation should exceed } 75 \% .22 \% \text { would accept the } \\
\text { mechanism for a small part of donation (less than } \\
20 \%) .\end{array}$ \\
\hline
\end{tabular}


Session $11-56$

Table 2: Sessions characteristics

\begin{tabular}{cccccc}
\hline Session & $\begin{array}{c}\text { Donation } \\
\text { percentage } \\
(d)\end{array}$ & $\begin{array}{c}\text { Producer } \\
\text { endowment } \\
\text { (red tickets) }\end{array}$ & $\begin{array}{c}\text { Official } \\
\text { exchange rate } \\
(1 / r)\end{array}$ & $\begin{array}{c}\text { Low } \\
\text { endowment } \\
\text { (yellow } \\
\text { tickets) }\end{array}$ & $\begin{array}{c}\text { High } \\
\text { endowment } \\
\text { (yellow } \\
\text { tickets) }\end{array}$ \\
\hline 1 & 0 & 73.33 & 1.5 & 1 & 10 \\
\hline 2 & 10 & 73.33 & 1.5 & 1 & 10 \\
\hline 3 & 30 & 73.33 & 1.5 & 1 & 10 \\
\hline
\end{tabular}


Session $11-57$

Table 3: Main results from the experiment

\begin{tabular}{ccccccc}
\hline Session & $\begin{array}{c}\text { Number of } \\
\text { effective } \\
\text { exchanges }\end{array}$ & $\begin{array}{c}\text { Official } \\
\text { exchange } \\
\text { rate }\end{array}$ & $\begin{array}{c}\text { Stated } \\
\text { exchange } \\
\text { rate }\end{array}$ & $\begin{array}{c}\text { Average } \\
\text { exchange } \\
\text { rate }\left(1 / r^{r}\right)\end{array}$ & $\begin{array}{c}\text { Ethical } \\
\text { dissonance* } \\
(\%)\end{array}$ & Piracy (\%) \\
\hline $1(0 \%)$ & 5 & 1.5 & 0.7 & 0.44 & 0 & 80 \\
\hline $2(10 \%)$ & 9 & 1.5 & 1.15 & 1.04 & 0 & 33 \\
\hline $3(30 \%)$ & 8 & 1.5 & 0.93 & 0.55 & 80 & 66 \\
\hline
\end{tabular}

*: We define ethical dissonance as the difference between the stated exchange rate and the real exchange rate, by hypothesizing that some participants could do an exchange different from their intentions. Even if the experimenter cannot directly see the stated exchange intentions, the "experimenter bias" could be present in the sense that a participant might want to give a positive image of himself and does a different thing once alone in the exchange room. The higher the ethical pressure (the higher the donation rate), the most frequent this phenomenon is likely to occur. 